\title{
Apoio matricial e práticas ampliadas e compartilhadas em redes de atenção*
}

Matrix support and extended practice and shared care networks in care networks Apoyo matricial y prácticas ampliadas y compartidas en redes de atendimiento

Gastão Wagner de Sousa Campos*

I á algum tempo, eu e a equipe com que trabalho temos nos debruçado sobre modos de operar, de agenciar e de lidar com relações intersociais, ou seja, na verdade, compreender como é que sobrevivemos em rede, como é que sobrevivemos à sociabilidade. Fala-se em rede, hoje em dia, na área da saúde, como um substantivo qualificativo, um substantivo adjetivado, como se fosse uma coisa boa em si mesmo. Mas viver em rede, viver em sistema significa se subordinar a alguma forma de controle ou mesmo a um importante grau de controle, de normatização e de ordenação da vida.

Um autor (Freud) antes de mim, mais velho um pouco, escreveu sobre o mal-estar na civilização, que é mais ou menos isso. Estou dizendo isso até para problematizar um pouco. Nós estamos sempre em rede, sempre em intercomunicação, estamos sempre em relação e há um dilema. Esse estar em rede implica fazer contrato, conflitos. Busco alguma forma para fugir de certa dicotomia que várias escolas, vários autores e a própria prática humana têm colocado ao pensar o social. Enfim, uma rede, ao operar de forma produtiva, seja lá o que entendamos por produtiva, para atender aos objetivos da missão primária, seja lá qual o objetivo dessa missão, em geral, algo voltado ao coletivo, deve também considerar o interesse de cada pessoa, do indivíduo. Enfim, o dominante, em geral, a opção que se tem encontrado na gestão, nas práticas de saúde, nas práticas pedagógicas é, de alguma forma, subordinar os menos poderosos, ou seja, reduzir ao máximo a autonomia, a liberdade, a condição dos sujeitos, das pessoas e aproximá-las de uma condição mais funcional, como máquinas. Há uma tradição na gestão inaugurada pelo taylorismo, mas

\footnotetext{
Conferência realizada em evento promovido pelo Pró-Saúde PUC Minas, em 2 de março de 2012, transcrita por Daniella Montes Dantas Lemos e Henrique de Oliveira Santos e revisada pelo autor. Na versão escrita, mantivemos o tom coloquial, próprio da fala oral.

* Professor titular da Universidade Estadual de Campinas, atuando com os temas anti-Taylor, democracia em instituiçôes, gestão de instituições. E-mail: gastaowagner@mpc.com.br.
} 
que já vinha de antes e que segue até hoje com a qualidade total, que pensa que, para operarmos ou trabalharmos em sistemas, em processos de trabalho, em rede, é fundamental ter quem mande, é fundamental ter um protocolo, é fundamental ter diretrizes e é fundamental que as pessoas funcionem como recursos. Como recursos humanos não são recursos, então é uma antiga tradição da gestão, ainda que bastante paradoxal.

A tradição do trabalho em saúde, particularmente da Clínica Médica, Fisioterapia, Enfermagem, Nutrição, e menos da Psicologia e do Serviço Social, é uma tradição também de comando vertical, de reduzir a pessoa subordinada à condição de ser dócil. A nossa prevenção, a nossa terapia, as nossas práticas costumam pensar o sujeito reduzindo-o a uma condição de objeto, algo que vamos diagnosticar. Enfim, trata-se de uma tradição de relações hierarquizadas.

Alguns autores, principalmente da Psicologia, de Pedagogia, desenvolveram uma tradição oposta, Paulo Freire da Pedagogia, Carl Rogers da Psicologia, com a ideia de que a alternativa a isso seriam formas não diretivas de terapia, de pedagogia, ou seja, certa horizontalização das relações. As pessoas que trabalham com grupos segundo essa perspectiva chamam-se facilitadores. São pessoas que ajudariam, mas que não teriam esse acento no controle.

Quando eu comecei a pensar no método de apoio Paideia, no apoio matricial, eu estava tentando fugir dessa polaridade, dessa dicotomia, e encontrar alguma forma de que, nas práticas clínicas, nas práticas pedagógicas, nas práticas de gestão institucionais, nós conseguíssemos compatibilizar um grau importante de autonomia, de liberdade dos trabalhadores, dos usuários, dos alunos, dos pacientes; enfim, e ao mesmo tempo, construir, no caso dos trabalhadores de saúde, certa responsabilidade sanitária, como que compatibilizaríamos a autonomia do profissional com os compromissos de ensinar, com o aluno, com a pesquisa, com boas práticas profissionais. Então, esse é um desafio, ou seja, de desenvolver modalidades, modos, modelos de gestão, de práticas em saúde, de práticas pedagógicas que pegassem o melhor dessas duas tradições, dessas duas vertentes, criando alguma coisa diferenciada.

Habermas teorizou sobre o agir comunicativo nas relações sociais, nas áreas de gestão institucional, trabalho em saúde, trabalho pedagógico, ou seja, áreas que dependem muito da comunicação interpessoal, mais do que da comunicação de deliberação, de criar contratos, de criar acordos sobre objetivos, sobre modos de fazer. São áreas que dependem muito de capacidade de escuta, capacidade de negociação, capacidade de tomar deliberação em conjunto, capacidade de avaliar, ou seja, de atuar de forma coletiva, articulada 
e integrada. Em um de seus textos, Habermas diz que o agir comunicativo depende de certa capacidade de diálogo. Para haver um diálogo, para haver uma relação dialógica, como sonhada por uma série de pessoas que pensam a possibilidade da democratização das relações institucionais, não só das relações macropolíticas, que pensam, então, a democratização da escola, da família, da clínica, da saúde e da vigilância em saúde, seria necessário o estabelecimento de isonomia nas relações. Habermas dizia que a condição para se estabelecer esse agir comunicativo, essa relação dialógica, essa relação interativa, e não opressiva, de dominação e de anulação da identidade do interesse, do desejo, dos valores do outro seria a simetria, não a assimetria. A assimetria das relações de poder inviabilizaria essa prática democrática. Parto de uma premissa diferente, ainda que busque também aumentar o coeficiente dialógico: a ideia do apoio Paideia de se viver em rede pode ser uma visão mais pessimista da vida. Para mim, acontece que a assimetria está sempre presente. Ou seja, a diferença de poder, a diferente capacidade de compreensão, de deliberação, de intervenção, de controle sobre o outro, de exercício do poder, no sentido amplo dessa palavra, sempre é algo assimétrico, ou seja, assimetria é constitutiva das relaçôes humanas e é constitutivo da sociabilidade.

Essa assimetria passa por diferentes capacidades de conhecimento. Em uma discussão de projeto terapêutico singular, de caso clínico, quando o tema predominante é a subjetividade, há uma assimetria a favor dos psicólogos, psiquiatras ou de quem tem formação em psicanálise ou cognitiva, em detrimento de um cirurgião, de um médico clínico e do enfermeiro de formação.

Há assimetria também pelo quanto cada um de nós está empenhado em uma tarefa pela diferença de envolvimento, de empenho, o quanto de desejo e interesse está colocado naquela tarefa. Há assimetria por diferente poder econômico e há diferença por diferente condição existencial. A relação entre profissionais de saúde, usuários e pacientes sempre será assimétrica. Um está doente, com risco, com dor, e o outro está se realizando enquanto pessoa, ganhando dinheiro, realizando-se como profissional. $\mathrm{O}$ mesmo ocorre nas relações entre o professor e o aluno. Há diferentes papéis, funções. Ainda quando se aposte em relações democráticas, elas nunca apagarão essas diferenças constitutivas dos sujeitos envolvidos.

$\mathrm{O}$ que proponho fazer, quando trabalho com a ideia de cogestão, de cogoverno, é criar, é pensar alguns arranjos, pensar alguns modos de deliberar, modos de analisar, de compreender, modos de fazer pedagogia, fazer a clínica, fazer a gestão e diminuir esse coeficiente de assimetria. Há uma série de propostas operacionais com essa finalidade. 
Vou desenvolver algumas aqui, mas sempre estará instituída essa assimetria. O problema é como a gente utiliza essas diferenças, se para a dominação ou para outras finalidades. $\mathrm{O}$ apoiador é alguém que tenta interferir nessas relações de trabalho, de gestão, tentando ampliar o grau de diálogo, de deliberação conjunta. Alguém que fica não nessa tradição vertical, o apoiador inclusive na clínica, desse modo, torna a relação clínica como uma relação de apoio. O papel do apoiar é o de colocar na roda, ou seja, de trazer esse não dito da assimetria para ser analisado, para ser compreendido e para ser falado e, ao mesmo tempo, produzirem-se leis novas que reduzam essa assimetria. Por exemplo, as leis de defesa da mulher. Há uma assimetria de gênero na sociedade ocidental capitalista, por isso precisamos fazer uma série de leis como a "Maria da Penha", uma série de direitos que diminuam essa assimetria ainda que mil anos de história e de machismo continuem operando. Apesar de todas as leis, nas relaçôes de gênero e na sociedade contemporânea, o menor tende a ser explorado do ponto de vista do trabalho e da sexualidade.

Nós precisamos criar leis e normas, e, ao mesmo tempo, aumentar a capacidade da mulher, do menor, do paciente, do aluno, do trabalhador frente ao governo, frente à gestão para construir agenda, colocar temas nas rodas, sua compreensão de deliberar de forma conjunta. Então, penso e tenho trabalhado com a ideia de que isso é uma visão importante do ponto de vista estratégico, buscando-se sociedades mais equitativas e mais justas. Nós temos que aumentar o grau de democracia institucional tomando a instituição em todas essas dimensóes. Temos que criar uma sociedade em que as formas de cogoverno e cogestão tornem-se cada vez mais possíveis.

Não somente a capacidade de escutar, mas a capacidade de escutar, de analisar, de falar, de agir e de deliberar de forma coparticipativa e de forma coarticulada, considerando as diferenças e essas assimetrias do ponto de vista do desejo. Nossos desejos são diferentes e singulares, existem interesses de classe, interesses de gênero, interesses de grupos de interesse. Existem diferenças culturais, políticas, ideológicas, de valores, de religiosidade. Acreditamos ser possível podermos construir nessas atividades práticas, na gestão do trabalho, na gestão do trabalho em saúde, da pedagogia, podermos construir objetivos complementares, podermos construir contratos que contemplem essa diversidade de interesse. Nem sempre é viável, mas, em geral, é possível.

Então a ideia do trabalho em rede, a ideia do apoio matricial, no caso da saúde, é pensar formas de trabalharmos de forma sistêmica, de forma orgânica, em rede, fugindo dessa tradição autoritária, dessa tradição de controle, que tão bem foi estudada por uma série de autores, como, por exemplo, Foucault e outros. 
Desse modo, comecei a trabalhar isso pensando a gestão da área pública e a gestão da área da saúde. $\mathrm{O}$ século $\mathrm{XX}$, eu sou do século $\mathrm{XX}$, apesar de estarmos no terceiro milênio, sou uma pessoa muito enraizada no século XX. Por vezes, eu nem noto que o tempo passou e que já estamos no terceiro milênio. Já faz quantos anos? Doze, mas é que o século XX é um século longo, como dizia Eric Hobsbawm (Mas, no século XX e no século XIX da Revolução Francesa, construímos os direitos humanos, a busca de igualdade, da democracia, da fraternidade, as políticas públicas de bem-estar social). Porém ficamos devendo a construção de metodologias de gestão da política pública e a organização dessa área pública. Vou usar um conceito rápido porque tem pouco tempo. Fracassou redondamente o modelo de gestão das instituições públicas, o socialismo real foi um desastre, a burocracia se impôs sobre um conjunto de interesses e valores. Em nome do bem-estar, tirou-se a liberdade, mas não se construiu o bem-estar. Boa parte dos sistemas públicos, mesmo em países capitalistas, como é o caso do SUS no Brasil, da universidade pública e da escola pública são privatizados sem a necessária privatização, são usados pela corporação médica, por corrupção, por clientelismo. Ou seja, qual o modelo de gestão da área estatal? A receita dos liberais e neoliberais é privatizar, devolver ao mercado, com isso a competição faria o que a gestão pública não conseguiu. Sabe-se que isso produz a selvageria, acabando com o planeta, produz o darwinismo social, eliminaremos os não competitivos, os idosos, os mais fracos, os menos estudiosos. Então nós sabemos que precisamos botar limite a essa tendência, à competição do mercado, atenuar e criar arranjos para se lidar com o conflito intergênero e interpessoas. As maneiras para se lidar com essa assimetria precisam ter uma normatividade, isso precisa ser construído, temos de desenvolver um modelo de gestão que amplie o grau de democracia institucional, mas que tenha um compromisso com a eficiência, com a produtividade e com a eficácia, cumprindo esse valor de uso das organizações.

O SUS precisa produzir saúde para a população e precisa garantir o bem-estar de seus trabalhadores, além de assegurar a sua realização, precisa sobreviver, criar viabilidade orçamentária como organização, a tripla finalidade das organizações. A PUC, que é uma organização privada, porém de função pública e comunitária, precisa se manter, não pode falir, mas precisa garantir certo grau de satisfação aos professores, não é só salário, mas realizações dos seus trabalhadores, professores e pesquisadores. Entretanto também precisa produzir valores de uso para a sociedade: pesquisa, conhecimento, livros e ensinamento para os alunos. Esses objetivos são compatíveis, mas também são contraditórios. Se centramos tudo na organização, nós vamos explorar 
os trabalhadores, vamos aumentar o capital, vamos diminuir a qualidade do produto, do valor de uso. Porém, se centramos tudo nos trabalhadores, teremos outros problemas. Como, por exemplo, nas Santas Casas do Brasil; os médicos as tomaram e estão matando a galinha dos ovos de ouro, estão matando a Santa Casa, diminuem a qualidade da atenção.

Eu estou procurando até hoje, com uma lanterna, organizaçóes centradas no usuário. Não encontrei ainda nenhuma. Apesar do controle social que há no SUS, mesmo assim não é comum predominar gestão centrada nos usuários. Mas tal centralidade seria viável? Alguns CAPS em Campinas, pelo menos, são tão centrados no usuário que os trabalhadores têm sobreimplicação e sobretrabalho. O conceito de sobreimplicação: os trabalhadores não se sentem com direito de tomar lanche sem ter o usuário ao lado, ou seja, não param de trabalhar às 8 horas ou 10 horas que estão em serviço. Ficam o tempo todo fazendo acompanhamento, terapêutica, consulta, etc. Então, nos CAPS da saúde mental em Campinas, há um desequilíbrio. Temos de pensar formas de cogestão e apoio. Na gestão, eu tomo o apoio como uma função gerencial que não elimina a coordenação, a avaliação, o planejamento, mas constitui outra função. Democracia institucional. Penso o trabalho clínico do mesmo modo, com a relação com o trabalhador sendo uma relação de cogestão, de redução de danos, de construção do diagnóstico, da temática e da terapêutica de maneira articulada. Penso também que o profissional de saúde, o gestor ou apoiador, o assessor, o professor não poder desconhecer as normas. Nós representamos o trabalho morto acumulado, temos de conhecer e discutir com o protocolo; contudo, para que seja uma prática compartilhada, eu não posso, numa relação com o usuário, quando ele fala, ignorar sua existência, sua fala: para mim, profissional, fumar é nocivo, isso é muito importante, sendo um idoso que está com hipertensão arterial, eu tenho de ouvir, tenho de escutar sua história pessoal com o cigarro. Não posso, em algum momento, deixar de colocar um saber que nós acumulamos, no caso, que o cigarro aumenta o risco de doença cardiovascular, diminui a expectativa de vida e aumenta o índice de câncer. Porém tudo isso deve ser problematizado de uma forma interativa.

O trabalho na gestão é a mesma coisa. Nós temos evidências internacionais de que o vínculo, de que a responsabilidade sanitária definida de forma formal, territorial e populacional, ou seja, a função de equipes de referência, de profissionais de referência, diminui a mortalidade, diminui a internação, diminui a medicalização, permite ampliar e qualificar o trabalho em saúde, isso é uma evidência. Então o gestor tem de chegar e trazer esses temas para o cotidiano, incluí-los no modelo de atenção. Entretanto sabemos que os médicos 
e os enfermeiros preferem ter uma inserção vertical, trabalham segunda-feira em um serviço, terça-feira em outro, quarta-feira em outro, transformando as enfermarias do Brasil em prontos-socorros. Vários serviços da família funcionam assim, o médico vai segunda e terça, não tem horizontalidade e possibilidade de construir uma atenção longitudinal. Há um conflito aqui, entre um saber acumulado em política de saúde e um interesse corporativo. Trabalho com a ideia de que o apoiador participa da construção da agenda, não é apenas um facilitador. $\mathrm{O}$ apoiador participa, interfere, discute, perde, ganha, cede, negocia, oferece análise, compreensão e explicação. No caso, o antagonismo entre diretriz normativa e o interesse de profissionais deverá ser trazido para a roda.

Defendo que o apoiador, o clínico, o pedagogo e o professor disputem participando do debate, da tomada de decisão. Um exemplo, vamos reformar o modelo pedagógico de um curso da área da saúde, só que minha experiência, meu conhecimento indicam que, nessa fase da formação de médico e psicólogo, vamos precisar ter prática, e essa prática tem de ser em mais de um cenário. Os alunos falam: "Não, professor, queremos ficar só aqui à noite e ter uma forma tutorial igual na Argentina, queremos só vir aqui e fazer a prova”. Eu falo "na saúde, não". Vai ter de atender paciente junto, essa forma centrada na teoria de formação não é adequada em saúde, vamos disputar isso, ou seja, valorizamos isso, tragam como ofertas, tragam para uma roda.

Então, trabalho com a ideia de que o tal apoiador opera tanto como mediador quanto como representante de projetos éticos, políticos e técnicos. Nós fomos inventando um nome para os facilitadores de cogestão. Quando se trabalha na gestão, nós chamamos de apoio institucional, apoiador institucional, por influência da análise institucional. Não deu para citar aqui, eu estou me baseando em uma série de autores, de escolas, no caso por influência da análise institucional, da psicoterapia institucional, de uma série de experiências de buscar a autogestão. Vocês veem que eu não trabalho com a autogestão, mas com cogestão e cogoverno. Redes de dependência e de graus de autonomia, redes de conflito, negociação, contratos e rupturas.

Enfim, chama-se de apoio institucional para a cogestão em organizações e movimentos. $\mathrm{Na}$ cogestão de relações interprofissionais, propusemos o apoio matricial. O apoio matricial é o cogoverno no tal trabalho de equipe. As pessoas me perguntam: Gastão, o que adianta montar equipe se, na equipe multiprofissional, há um médico que tem mais poder do que o enfermeiro e, diga-se ainda, do que o agente de saúde, é isso que eu estou dizendo, essa assimetria está constituída, o médico é um profissional universitário que tem essa tradição, tem essa história, só que é melhor discutir projeto terapêutico, 
a clínica e o diagnóstico de forma inter do que deixá-los exclusivamente em mãos de uma categoria profissional. Os agentes de saúde vão ficar seis, oito meses calados. Cabe ao apoiador problematizar o que está acontecendo, colocar na roda, criando um arranjo que faz projeto terapêutico de forma interprofissional, não só os enfermeiros e os médicos, mas cria esse arranjo, põe para funcionar todas as contradições, toda essa assimetria social, culturalmente produzida.

Toda a instituição, toda a organização, toda a família, toda a equipe que disser que não é assimétrica está mentindo e escondendo uma forma de dominação. Entrevistem, por exemplo, os agentes de saúde. Em geral, eles estão morrendo de medo do médico e do chefe. É um totalitarismo que leva a essa impossibilidade de trabalhar a assimetria, a diferença de poder, a diferença de interesse, a diferença de desejo. Só que coloco, cabe ao apoiador uma postura ativa, interativa. A esse ativismo eu chamo de oferta, e a oferta é estimular as pessoas a se autorizarem a refletir criticamente sobre o que o outro, seja apoiador, seja da gestão estão trazendo.

Quando fui secretário de Saúde em Campinas, entre 2001 e 2002, eu já tinha isso mais ou menos desenvolvido. Campinas não tinha estratégia de saúde da família, tinha um modelo tradicional de atenção básica, o modelo da John Hopkins baseado em programas. Eu falei, a Estratégia de Saúde da Família é muito mais eficaz, eu vou trazer essa política como oferta. "Você é chefe ou não é?", perguntaram-me muitos. Eu falei, eu sou chefe para "burro", só que aqui já existe um passado, uma tradição. Nós não vamos apagar essa tradição, ela tem valor, mas vamos misturar essa diretriz do Ministério da Saúde do SUS com essa tradição de Campinas, ela, a organização por programas, não é só desgraça e corporativismo, não é só atraso.

Então, a atenção básica em Campinas vai ter outra cara, vamos singularizála, e o ritmo de construção vai ser diferente em cada região, em cada equipe, em cada território. Uns aderiram no primeiro e no segundo mês, porém ficaram duas ou três unidades que até hoje são diferente. Inclusive as que foram vendo que as vantagens da nova estratégia, estão tendendo a mudar, essa paciência que os administradores nem sempre tem é essencial à democracia. É a mesma coisa na prática clínica, eu falo, uma clínica ampliada e compartilhada. O que é uma clínica ampliada e compartilhada? Trabalha-se com a ideia de redução de danos, eu trago a ideia do cigarro, mas se o paciente diz que o cigarro é fundamental, eu falo, então vamos fumar nas horas fundamentais, divertindose, não fumar trabalhando. Tomar vinho para mim é fundamental, então vamos tomar vinho. Em vez de tomar uma garrafa por dia, vamos tomar meia. Vamos tomar nos momentos de celebração. Nesse dia, você diminui 
tal remédio, aumenta esse outro, então esse jogo, essa interação não é só do facilitador, é uma interação interativa. Aliás, não é ativo nem passivo, é interativo, porque, nessas metodologias não diretivas, o professor, o clínico, o promotor da saúde fica muito na dependência do protagonismo do outro, o ativo é outro polo, o ativo é o aluno, chamam metodologias ativa. $\mathrm{O}$ apoio é uma metodologia interativa.

O professor também faz algo. Eu, como professor, não renuncio, não ponho os alunos só para dar seminário. Eu digo "vocês dão seminário, mas eu falarei como eu estou falando aqui. Sou mais velho que vocês e estudei mais, por isso, tenho obrigação de ter preparado o tema mais do que os alunos". Deixo temas livres para irmos construindo com os alunos, inclusive da graduação, em que $80 \%$ dos temas estão definidos. Na pós-graduação, dou $60 \%$ do programa e deixo $40 \%$ das aulas abertas. Então procuro criar formas que permitam essa cogestão, esse cogoverno, dessas relações de poder, dessas relações de rede assimétrica. A mesma coisa que estávamos conversando hoje, como é que a universidade vai fazer uma formação prática dos alunos, utilizando a casa dos outros como cenário de práticas, a casa dos outros é o SUS, tem de ser cogestão, tem de se fazer contrato coma as equipes e com os gestores, tem de se deliberar junto, tem de analisar os problemas juntos, tem de se falar sobre o não dito.

Uma estratégia bem pragmática que faço para montar essas rodas é construção da agenda. Cada grupo de interesse põe um tema, o apoiador ou o gestor põe outro, o usuário põe outro, o trabalhador põe outro e o agente de saúde põe um. $\mathrm{Na}$ intervenção, procura-se acatar as várias partes. Em um hospital municipal de uma capital do Sudeste, eu ajudei um pouco a trabalhar essa coisa da cogestão. Havia uma área de traumatologia, por exemplo, organizouse interprofissionalmente e procurou-se fazer um diagnóstico compartilhado. Quais são os problemas? Infecção hospitalar está alta demais, eram esperadas oito e estava em trinta e tanto, a média de permanência está alta, então vamos explicar esses problemas. São indicadores de resultados muito simples, mas podem indicar alguma coisa interessante. Vamos ver como compreender esse contexto. Os médicos ortopedistas diziam o seguinte, sabem por que isso está assim? É por causa do governo, da diretora, da Secretaria Municipal que não põe verba, que não compra isso, que não compra aquilo. As enfermeiras, fui conversando, sabem por que está assim? Doutor Gastão, os médicos são uns "porcarias", são uns vagabundos, saem com a roupa do centro cirúrgico para ir ao café, não lavam a mão, não conversam, não fazem prescrição na enfermaria e vão embora. Conversei com o diretor. Ele disse: é porque o servidor público não se empenha; sabe como que é o servidor público, só 
quer salário, preocupar mesmo com o paciente, com o usuário, não preocupa. É realidade, quando se reuniram esses autores na presença de um mediador, conseguiu-se construir uma explicação que continha todas essas perspectivas, pois eram parcialmente verdadeiras.

Por isso acho que um papel importante do apoiador é construir o que eu chamo de espaço coletivo, o nome vulgar disso é roda, vulgar não, brasileiro. As rodas lá no Paulo Freire. Então você construir um espaço coletivo, que não é apenas um espaço coletivo de cogestão, estamos também fazendo uma educação e uma formação. Então, espaço coletivo implica tema, análise, discussão, interpretação, deliberação, contrato conjunto e definição de tarefa. Então, para o apoiador, o grande desafio é formar esse espaço coletivo, vamos reunir os grupos de interesse, ou seja, os interessados em melhorar o atendimento de traumatologia, na urgência, na enfermaria. Vamos ver se conseguimos juntar, andando, parado, 15 minutos, e criar um espaço coletivo, com gestor, com enfermeiro e vamos juntar esse discurso. $\mathrm{O}$ apoiador tem de tentar fazer com que tudo isso não vire guerra civil, porque, se virar guerra civil, perdemos. Se a fala do ortopedista ofende o gestor, se a do gestor ofende o trabalhador, então devemos encontrar uma forma de espaço protegido. Vocês já ouviram isso do pessoal da Psicologia, um contrato para dentro, que se consiga tratar de crítica, tratar de problemas sem necessariamente passar pela liquidação do outro. Sempre sangra um pouquinho, o debate, mal-estar, sempre sangra, mas que se consiga chegar a um acordo.

Qual é a verdade? Com quem estava a verdade no caso do hospital, com o ortopedista, com o enfermeiro ou com o diretor? A verdade estava nesses três discursos, os três tinham razão, só que tinham razões parciais. Nós temos de fazer um projeto estratégico, algum investimento, sim, era necessário. Botar não sei o que no centro cirúrgico, não tinha ar condicionado, estava quebrado. Os médicos precisavam de uma reeducação para a assepsia, estavam fazendo essas coisas de maneira inadequada, de fato... Não estavam fazendo visita do paciente, tem de lavar a mão direito, usar a escovinha, mas quem vai supervisionar isso, a enfermeira? A enfermeira vai me ensinar a lavar a mão? Vai sim. Só que eles também tinham razão, faltavam coisas. O diretor também tinha razão, enfim.

Essa capacidade de construir-se uma compreensão complexa, ela pode ser viável na vida e ela diminui um pouco essa "aspereza", porque nós temos um objetivo em comum, que é criar um espaço de trabalho que seja melhor pra nós todos, que possamos publicar o resultado de nosso trabalho. Que possamos ser reconhecidos. 
Então, a ideia do apoio matricial é muito isso. $\mathrm{O}$ interprofissional, a relação interprofissional em rede. Somos acostumados com regulação, é computador que regula, é a norma, é referência e contra referência, manda pra cá, manda pra lá e interconsulta sendo no mesmo serviço, o ortopedista fala, esse cara aqui é doido, chama a psicóloga, pede uma interconsulta, escreve, leva três meses, dois meses, em 15 dias já se matou, suicidou-se, já pulou do terceiro andar, já foi embora, não aderiu ao tratamento. Vem a psicóloga faz, escreve, o ortopedista já foi embora, já é outro, já não está aí. Desse modo, não cria esse espaço coletivo interprofissional. Então a ideia do apoio matricial é personalizar essas relaçôes, criar uma dinâmica de interação dialógica, reconhecendo o núcleo e o papel de cada um, as diferenças. Só é possível trabalhar em cogestão, fazer apoio se reconhecêssemos o outro como pessoa, isso é Gandhi, se eu acho que o outro tem valor de uso, valor de uso é um negócio bem pragmático, ortopedista tem algum? Sim, nós precisamos de ortopedista, apesar de a maioria agir apenas na dimensão do biomédico. Por outro lado, o ortopedista precisa reconhecer que o psicólogo tem valor de uso, estou falando porque é polo. Se nós não achamos que o outro não vale nada, não tem cogestão, não tem apoio, mais do que valer alguma coisa, reconhecer como pessoa é reconhecer que se precisa do outro em alguma medida e que é possível construir certo grau de confiança e que, apesar disso, teremos diferenças e atritos. Tem de ter certo cuidado com outro, porque, se alguém abaixar a guarda, há risco de assédio, de poder dominar. Vocês viram que eu não uso muito o conceito de empoderamento. É perigoso isso, porque a diminuição da assimetria passa por aumentar a capacidade de análise, decisão e deliberação dos vários grupos, ou seja, passa por certo empoderamento.

O problema é o que fazemos com o poder. Nós, seres humanos, montamos nas costas de outros que têm menos poder. Então o movimento negro, escravagismo, essa coisa toda. Aí houve uma afirmação fundamental de que black is beautiful, vamos criar leis de discriminação positiva, racismo é proibido... Quando vai ficando com o poder, o que se faz com o poder que estão adquirindo? Vira racismo contra branco? Eu sou branco, como é que faz? Eu não quero isso. $\mathrm{O}$ que se faz com o poder de um grupo que vai ascendendo? Cito um exemplo de luta por direitos que deu certo, eu acho que há um aumento da capacidade de negociação, de contratualização, de autoestima, de defesa de si mesmo dos afrodescendentes no Brasil, não em geral, mas como tendência. É óbvio que isso é heterogêneo, depende do lugar, da instituição, da família, da pessoa, etc., etc. Só que, e o outro, e o japonês, e o índio, e os "branquelos", e o não sei quem? Então, eu acho que esse é um tema que parece bastante utópico e é. É uma estratégia de reconstrução 
democrática da sociedade. Agora, a experiência tem me indicado que a luta pela democracia institucional, pela cogestão, a metodologia de apoio são estratégias que têm valido a pena. Os casos relatados por vocês com o apoio matricial, que estão construindo no SUS BH e na PUC, são muito interessantes. Uma coisa importante no apoio para montar o espaço coletivo é fazer um contrato entre o pessoal envolvido, porque, na verdade, apoio e cogestão é construção. Comento o apoio matricial em uma capital do Nordeste com $80 \%$ de cobertura de saúde da família, com um projeto "em defesa da vida". Várias pessoas fizeram curso em Campinas e tentam fazer cogestão. Aí fizeram concurso para apoio matricial, encheram de psicólogo, fisioterapeuta na atenção básica. Após três meses, me chamaram: "Gastão, pelo amor de Deus, você falou essas coisas, porém aqui está o maior desastre, igual guerra civil. Metade das equipes de saúde da família não quer ver esses psicólogos, fisioterapeutas nem pintados de ouro". Eu falei, vamos sentar lá e ver o que foi, tem o seguinte, tem os problemas, por exemplo, a maioria do pessoal foi contratada, fez seleção, não teve formação, não teve contrato e chegou à equipe de saúde da família. Chegou a psicóloga dizendo: olha eu fiz um concurso, eu sou a psicóloga de vocês, viu bem! E todo o problema de subjetividade é comigo.

Eu estou falando isso porque parece que só médico é assim, então todo o problema de subjetividade agora é comigo, tá! E eu vou vir na reunião de vocês... Só que vem na nossa reunião coisa nenhuma, ela diz que vai supervisionar meus casos clínicos, vocês acham que nós somos o quê? Fora daqui, não queremos você, não queremos a fisioterapeuta... Há uma caricatura, estou dando ênfase aos problemas. Em muitas unidades básicas, os núcleos de apoio conseguiram integrar-se de modo adequado. Onde houve conflito, houve de se retomar o processo, fazer junto modos de operar o apoio.

Ou seja, então a coisa do contrato, você tem que fazer oferta, vocês querem uma psicóloga aqui? Como que chega? O Ministério diz que chega sim, danese o que o Ministério diz, essa é a oferta, como é que eu chego? Só faço educação permanente, só faço supervisão, chego à reunião junto, vamos fazer visita juntos. Então é a coisa da contratualização. Você tem uma oferta, você tem um suposto saber sobre a subjetividade, em saúde mental, em Fisioterapia, você tem uma suposta capacidade de apoio, você tem um suposto programa, você tem uma suposta ajuda, apoio é ajudar, mas é empurrar também. Enfim, o espaço coletivo implica em certo acordo. Antes de eu botar um enfermeiro, um ortopedista, as diretoras, a gestão, nós fizemos um acordo, no hospital onde prestamos apoio, vocês topam conversar? Topa fazer um projeto de intervenção juntos e articulado? Fazer um diagnóstico juntos? Vamos tentar 
não ofender um ao outro, trabalhamos juntos, não precisa ser amigo no trabalho, mas também não dá para ficar muito áspero. Nós vamos ficar aqui muito tempo, um ano, dois anos, oito anos, vinte anos.

Então, como é que se faz isso? Nós temos um objetivo em comum que é melhorar o nosso trabalho, o nosso salário, nossa legitimidade. Estamos trabalhando essas coisas de apoio, e é muito importante a reforma institucional, pensar em instituições que facilitem essa cogestão e não dificultem, como são os organogramas, as normatividades da maior parte das instituições hoje. Então há uma polêmica, é a postura ou é a estrutura, são as duas coisas. Nós precisamos reformular a estrutura, o Conselho Municipal, Conselho Nacional de Saúde, equipes como espaço de deliberação. O pessoal fala: nós somos deliberativos, então vamos mudar uma norma do SUS. Eu falei, não. Assim vocês vão brigar para mudar, vocês são deliberativos para quem está na roda, para quem está no espaço, para quem não está, vocês vão conversar, seduzir, pressionar, lutar, nós vamos criar um contrato que, entre nós, isso fica deliberativo, não para outra equipe, não é para o Conselho Municipal, não é para o outro serviço.

Então é preciso reformas para que a clínica ampliada seja viável, ambulatórios, centro de saúde, a maioria dos profissionais tem de ser diarista, você tem de ter tempo, não pode ser pronto-atendimento. $\mathrm{Na}$ urgência e emergência, é outra lógica de trabalho, é mais focada para salvar vida, para diminuir a dor. A nossa lógica é para construir bem-estar, o bem-estar tem uma parte objetiva, que são anos de vida, mas tem outra parte subjetiva, que é essa interação com o outro, demora tempo e adesão ou a não adesão. Então nós vamos precisar de equipes nas enfermarias, na terapia intensiva, de plantonistas à noite, nos hospitais, etc. $\mathrm{O}$ atendimento dessas condições estruturais e normativas significa que vai ocorrer cogestão e apoio? Não, você pode montar essas condições e não se passar a outro modelo. Se não tem as condições, fica muito difícil fazer a reforma.

Era isso em linhas gerais. Agora eu queria ouvir vocês. Vocês têm um minuto para me fazerem um conjunto de perguntas (risos). Desculpa, não está democraticamente distribuído o tempo, mas falem vocês um pouco. Eu escuto todos e respondo.

\section{Debate}

Pergunta 1: Gastão, eu sou Deonara, trabalho na equipe de humanização e sou funcionária da Secretaria Estadual de Saúde. Uma coisa com que fico preocupada é a grande tendência da saúde, de até mesmo nas unidades 
básicas, saúde da família, de uso do protocolo. Qualquer atendimento você só faz se tiver protocolo. Não conseguimos, efetivamente, ter espaços para o que não está no protocolo. O que não está no protocolo você não faz. Há essa cultura nas instituições de saúde. Outra coisa que percebemos é que os profissionais não conseguem ouvir nem o que os outros têm para falar, nem o que os usuários têm para falar, principalmente as usuárias têm para falar. Então, como criarmos uma abertura para termos formas de atenção que não esteja só no protocolo?

Gastão: No sentido mineiro da palavra, não se pode implicar muito contra o protocolo. Implicar é se envolver, mas, para os mineiros e goianos, implicar é ficar contra.

O que é o protocolo? O bom protocolo é uma síntese do trabalho morto, da experiência anterior. Quando você está atendendo, é o tal trabalho vivo, criou um jargão entre nós que trabalho vivo é santo, é bom, é ótimo, e trabalho morto é o bandido. Eu brinco, quando o professor batia a palmatória, era trabalho vivo, baseado num protocolo morto que a disciplina se construía com violência. Então um bom protocolo, diretriz clínica, um bom planejamento, são orientaçôes que não devem ser ignoradas, é alguma descrição de modelo de atenção. Agora o protocolo deve ser singularizado porque a prática de saúde é práxis, não é techné, não sei se vocês se lembram disso, não dá para desenvolver aqui. Techné, Aristóteles, o velho lá, você pega o marceneiro que aprendeu a fazer uma mesa de quatro pés, você faz a mesa bem. Agora você vai fazer clínica, você vai fazer governo, gestão, política, você vai fazer justiça. Houve um homicídio, precisa ver por que matou. Se foi em legítima defesa, tem a lei que é proibido matar, ou seja, o protocolo, mas tem de ter alguém como um mediador que é práxis, que vai ouvindo o contexto, as pessoas envolvidas e as testemunhas têm de interagir com o singular. Por isso precisamos da história de vida.

Um professor aposentado, professor Ronan, no primeiro dia de residência, eu também fiz clínica médica, tenho esse pecado, é porque aqui eu sei que há poucos médicos, então já faço demagogia para ganhar voto. Estou brincando... Mas esse professor dava o protocolo de diabetes, caso grave dependente de insulina, aí ensinava e repetíamos e estudávamos, e depois íamos atender os casos. Quando voltávamos, o professor perguntava: seguiram o protocolo corretamente? Sim, professor. Ele saía correndo pelo corredor. O que foi professor? Vocês seguiram o protocolo, então vocês mataram alguns, fizeram muita coisa desnecessária e deixaram de fazer outras. Todo ano, ele fazia 
isso no primeiro dia. Não dá para ignorar isso, você tem de saber sobre a racionalidade da práxis, por isso que é assimetria. Há a obrigação de saber sobre o passado, sobre as pessoas e também sobre a experiência que, em geral, está nas diretrizes e nos protocolos. Haverá alguns muito ruins, mas está acumulado nesse saber. É a relação da prática com o saber. Porém quem faz clínica, gestão, Pedagogia tem obrigação de singularizar isso em função situacional, de recriar. Por isso é muito responsável o trabalho do juiz, clínico, professor, por isso precisamos de certo grau de autonomia. Por exemplo, a ideia do MEC de melhorar o ensino fundamental, transformando-o em uma máquina, padronizando o que cada professor de Matemática vai fazer pelo Brasil afora, aí estamos perdidos.

Portanto, essa relação é isso, a coisa de acostumar a ouvir. Nós pouco ouvimos porque a prática profissional é arrogante, é autoritária, tem poder, mas não ouvimos também porque é difícil, você ouve e vai fazer o quê? Meus alunos de Medicina falavam: "Professor, por que tenho de perguntar se o paciente está empregado, se é pobre? Eu não sou o Lula, o que eu posso fazer?". Você tem de perguntar por que, suponhamos, que seja um carioca, não um paulista, você pergunta: "Você está desempregado?" "Estou." Aquilo deprime a pessoa, não é digno. Estou fazendo um estereótipo, mas o emprego tem tudo a ver, vai construindo a história de vida, é hipertenso, é diabético, o estresse, a emoçãa, o afeto, a depressão vai afetar esse negócio todo. Você não vai resolver os problemas, mas se pode trabalhar o tema de o que se vai fazer com isso.

Então, precisa criar as condições, não dá para o computador fazer toda a agenda dos médicos de família, dos enfermeiros, como, às vezes, os reguladores querem fazer. Agenda é o número de encontros, fazem parte da estratégia terapêutica. O pré-natal e o parto que foram citados na pergunta, chegamos a algum lugar e dizem aqui se segue o protocolo, toda gestante tem sete atendimentos. Aí eu falo "que droga!". Uma tem de ter três e a outra vinte e oito, ou seja, acompanhá-la toda semana. Não está no protocolo. Às vezes, o risco é orgânico, ela é obesa ou hipertensa; às vezes, o risco é subjetivo, a mulher não tem companheiro ou não queria ter o filho; às vezes, o risco é social, a mulher quer ter o filho, está super a fim, não tem nenhum problema orgânico, mas está em uma "desgraceira", mora em um lugar que está cheio de gente ou tem violência doméstica.

Desse modo, a relação da equipe com cada um se faz por meio de diagnóstico ampliado. É necessário escutar o outro, ouvir, interagir, ter várias estratégias terapêuticas. Isso depende da formação. Por isso, discutir o caso ajuda a aprender a ouvir o outro, escutar de novo. É normal ficarmos com medo. A 
discussão de caso é uma forma de controle social, falamos de nossas clínicas com os outros profissionais, inclusive de outras especialidades. Quanto mais burocratizado, menor é o agir comunicativo, menos circula. Fica você com sua consciência, o profissional e a sua consciência para o bem ou para o mal, em geral para o mal do enfermo e do paciente. Então são algumas coisas bobas, simples, mas que são da nossa tradição. Quem vai ser contra discutir caso? Vamos parar de trabalhar uma ou duas horas e discutir caso. Diante disso, amplia-se o conceito de discutir caso, tornando-se multiprofissional, trazendo a dimensão subjetiva e os protocolos. Mudar um protocolo é um ato muito sério, não deve ser feito sozinho, precisa ser compartilhado com alguém, porque não é simples. Por exemplo, se é uma boa diretriz, um bom saber, é um trabalho morto, ou seja, um "bando" de gente que fez aquilo antes e o experimentou.

Enfim, eu acho que nós devemos lidar com isso dessa forma dialógica, os profissionais que trabalham com a AIDS estudam e sabem tudo do protocolo mundial, internacional e da OMS, só que eles falam que já foi consensuado, nem é caso a caso. Eles pegam aqueles negócios da Suíça, que vêm de Genebra, sentam e falam: "Aqui, em Belo Horizonte, esse negócio cabe ou não cabe, é viável ou não é viável”. Diante disso, já se faz uma primeira adaptação geral ao contexto singular e aos recursos que se têm. Que apoio nós temos? Há saúde mental aqui? Pessoal da atenção básica tem de lidar com transtorno grave de saúde mental? Eu falo "vareia" como dizia o Adoniram Barbosa, um sambista de São Paulo, as horas "vareiam". Mas, "vareia" mesmo! Você está no Amazonas, no meio do mato, tem um distúrbio psiquiátrico grave e tem apenas a família, a tradição e o médico de família para lidar com o problema. Então vão ser usados a tradição e o médico. Porém, um lugar como Belo Horizonte, que é cheio de CAPS, psicólogo, lacaniano, há ajuda, não muito, mas ajuda... Estou brincando. Então, não tem sentido sobrecarregar a ESF com surto e transtorno mental grave, a não ser que o vínculo, o manejo e o conhecimento do paciente sejam ótimos, porque isso não é uma questão puramente técnica, mas não como regra. Agora, em outros lugares, é regra. Enfim, isso que é difícil, nós seres humanos, principalmente da gestão burocrata, temos muita dificuldade de fazer essa singularização com responsabilidade e de forma interativa, por isso é um exercício e um aprendizado dependente muito dos gestores. O gestor morre de medo disso, porque cria outra dinâmica, e o gestor fica exposto pela criação de discussões de gestão.

Eu fiquei chocado na $14^{\circ}$ Conferência. O povo grita desaforos um com o outro, maltrata-se, não tem tempo dialógico. Vocês já fizeram movimento estudantil ou de partido? Já vem tudo pronto antes e só se vai para contar os 
votos, porque não se faz pela Internet. Tem a tese um, dois e três, ninguém escuta a outra ou compõe. Então, na Conferência, foi a mesma coisa. Óbvio que é alegre, porque são três mil pessoas a favor do SUS em apenas um lugar. É muito bom, todo mundo se parece. Porém há muitos maus-tratos e desrespeitos, e não há muito aprendizado. Vai ganhar quem tiver a maioria. Se a maioria for contra o aborto, ganha. Ninguém escuta o outro, porque tem um minuto, dois minutos e começamos a falar, entretanto o adversário começa a gritar, faz estratégia parlamentar, pede questão de ordem e começa a falar do regulamento. Estou desviando do assunto...

Pergunta 2: Qual a sua opinião dos cursos de graduação e gestão em saúde?

Pergunta 3: Boa tarde, meu nome é Cláudia, sou coordenadora do apoio matricial de Santa Luzia, que fica na Região Metropolitana, e a minha pergunta vem da nossa prática. Temos cinco anos de apoio matricial e, nas discussões e avaliações feitas em equipe, percebe-se extremamente essa potencialidade do dispositivo do apoio matricial, que é muito perceptível e nos anima a continuar. Porém, evidentemente, nós enfrentamos muitas dificuldades e desafios na prática, e particularmente a questão da rotatividade profissional, sobretudo na saúde família, e menos no apoio matricial. Aliás, no apoio matricial, quase não tem essa rotatividade, mas, na saúde da família, ela é percebida como um empecilho para potencialidade desse dispositivo em ação.

Então, na verdade, minha pergunta é assim, talvez no fundo, eu queria ouvir algumas palavras otimistas de algum atenuante, algum exemplo de práticas em outros lugares que você tenha visto ou contornos para esse impasse e para essa realidade que vivemos tão veementemente com essa precarização das relações de trabalho no SUS. Então essa é uma pergunta.

E a segunda, não tem relação direta com a anterior, gostaria de ouvi-lo um pouco sobre essa diferença entre o apoio matricial e o apoio institucional.

Gastão: Cursos de graduação: a Unicamp propôs, e eu até coordenei um comitê e montamos uma proposta. Só que os cursos de saúde coletiva de graduação são uma experiência nova e precisamos de prudência sobre o conteúdo. Primeiro que acho que não é só gestão tem a vigilância em saúde que é especializada. Apesar de todo mundo ter de fazer saúde coletiva, clínica ampliada e promoção, há algumas coisas que são especializadas de epidemiologia, de educação em saúde e também de gestão, e, hoje em dia, esse povo é só de pós-graduação, residências ou cursos de especialização, ou ainda mestrados profissionais. 
Eu acho que pode ter essa profissão como curso de graduação que inclua a vigilância em saúde, já que o SUS está cada vez mais complexo, não para ser o chefe, mas para ser assessor, apoiador de avaliação, de planejamento, de territorialização, de controle de epidemia, de controle de fábricas, de meio ambiente. Enfim, temos uma vida cada vez mais complexa. Entretanto os cursos com essa questão de aumentar as vagas sem aumentar as condições, a maioria dos cursos são à noite, nada contra ser à noite. Por que digo isso? Porque é um ofício e precisa ter prática, então nosso curso teve até a parte teórica à noite, só que havia doze horas por semana práticas. Começava-se pela atenção primária, depois passava pelas equipes de vigilância em saúde. $\mathrm{O}$ aluno de graduação tem de fazer isso. Como que se forma alguém em saúde só com a parte teórica? Eu sei, por exemplo, que tem fisioterapeuta que é formado assim, mas temos de endurecer a cobrança. Ofício se aprende fazendo em conjunto e com supervisão de pessoal competente. Essas profissões são aplicadas sobre seres humanos. E como a formação de pedagogo não tem um estágio grandíssimo em escolas, tem de ter esse estágio igual aos nossos. $\mathrm{O}$ acadêmico precisa ficar internado na escola dois anos do lado dos professores, da supervisão, dando aula para "moleque" da periferia, "moleque" selvagem, comum, da classe média.

Desse modo, do ofício devemos cobrar prática, inclusive nesses cursos. Vamos dar um jeito de ter bolsas para alunos, facilitar o acesso dos que não sejam da classe média e os pais não podem pagar. Mas tem de praticar, ou seja, não pode ser essa carga horária, não pode ser do jeito que se está se fazendo.

Agora a outra pergunta. Primeiro sobre a precarização. Eu não encontro palavras otimistas para atenuar os imensos danos e os malefícios da precarização e do desrespeito do SUS com os seus trabalhadores. Não tenho otimismo, esse é um dos fatores que está travando a reforma sanitária, a diferença de Belo Horizonte é que vocês são estatutários. Essa é umas das únicas cidades do Brasil que as ESF, acho que $90 \%$ a $100 \%$, são estatutárias e tem carreira, essa é uma diferença brutal. Campinas foi assim até 2002 ou 2003, porém o Ministério Público obrigou a demitir 1500 pessoas, de uma vez só, entre médicos e enfermeiros. Treina-se, forma-se e se capacita na assistência, e o povo vai embora. Há pouco tempo mandaram 400 enfermeiras embora porque fizeram um concurso tipo seleção pública em vez de fazer concurso. Passaram-se dois anos, o Ministério Público não autorizou, e mandaram todos embora. Eles até tinham feito curso na Unicamp, que tem oferecido capacitação aos profissionais da rede. 
O apoiador precisa ser formado com o mesmo cuidado com que o Freud formava os seus psicanalistas, até mesmo maior, porque a metodologia de formação de terapeutas precisa ser adaptada para agora. Lá trabalhamos com a ideia de formação dos apoiadores. Eles precisam de colo e de ombro. Colo é complicado, precisam de ombro. Colo é para criança, ou seja, precisam de apoio. Como fazemos isso? Discutindo os casos, questionando por que você foi lá com essa equipe e não foi com a outra, sugerindo textos teóricos que expliquem a formação do espaço coletivo, textos sobre como lidar ou mediar conflitos, trazer uma oferta e ficar firme, trazer um tema polêmico e que desagrada.

Além do núcleo, por exemplo, sou fisioterapeuta, sou psicólogo, sei muito de transtorno mental, sei muito da dinâmica familiar, mas, além de precisar saber isso, precisa saber de grupalidade, dessas coisas todas que eu estou falando, governo de si mesmo, cogoverno de si mesmo, cogoverno dos outros. Isso se forma fazendo a prática, com alguém que está fora, com alguém que está com mais experiência. Então nós estamos fazendo isso.

No apoio, quando há rotatividade alta, é muito mais difícil fazer um contrato, pois, quando mudam as figuras importantes, muda a dinâmica inteira, não começa de novo, mas volta para trás. Então é como enxugar o gelo.

Pois bem, qual a diferença entre apoio matricial e institucional? É que um é matricial e outro é institucional... Estou brincando! É o seguinte, apoio institucional é mais difícil. Por exemplo, fui chamado a um hospital municipal de uma capital para fazer apoio institucional, ajudá-los, apoiar um processo de mudança. Eu tenho minhas ofertas, minhas ideias, autorizavam-me a criticar, só que eu não sou empregado deles. Tinha mais autonomia e possibilidade de aliar-me aos usuários e trabalhadores com maior liberdade. No apoio institucional, quando é o gestor que vai fazer isso, o gestor tende a valorizar mais o projeto governamental (a maioria dos gestores é cargo de confiança) do que a dinâmica dos trabalhadores e mesmo dos usuários, é mais delicado o agente conseguir na cogestão sendo gestor, é mais difícil e mais tenso o agente fazer esse papel quando o apoiador institucional é funcionário com cargo de confiança. Em Campinas, pegamos os supervisores de Enfermagem, de tuberculose, de Odontologia e os capacitamos para trabalharem com apoio, só que eles são funcionários, e supervisor é um cargo de carreira, de carreira não, é uma cargo de confiança do secretário, então cada distrito, cada região de saúde tem 10 a 12 . Em vez de chegar lá e fiscalizar, dá ordem, dá esporro. De vez em quando, dá um curso, vai lá fazer junto. Melhorou, mas tem um problema: quem não implantou a política do governo é porque é vagabundo, 
da oposição e traidor, seja lá qual for o programa de governo. Às vezes é um bom programa, às vezes é um ruim. Então, o apoio institucional, ele tem essa tensão entre o papel do gestor e as equipes. É preciso colocar em análise, e se ele tem muita autoridade, não deixa colocar isso em análise, não deixa isso entrar na roda, não entrar como tema nunca. Assim a avaliação do gestor nunca entra como tema, entra a avaliação dos médicos, dos enfermeiros, dos agentes, mas do gestor nunca entra.

No apoio matricial, o conflito é esse que a colega anterior falou na saúde coletiva, que é o conflito. $\mathrm{O}$ poder do saber das várias disciplinas da Fisioterapia, da corporação da Fisioterapia, da Medicina, dos generalistas, dentro da medicina dos generalistas, dos pediatras, dos enfermeiros; então o apoio matricial lida mais com esse conflito de profissóes, e a fortaleza do apoio matricial é o compromisso com a saúde, com os usuários, é trazer a centralidade do usuário nessa discussão da clínica, das práticas, tentando atenuar um pouquinho as corporaçōes. Eu acho o apoiador matricial mais autônomo da instituição, ele está preso na organização do governo, do gestor, mas ele está preso em geral à sua corporação. Há vários apoiadores matriciais, eu fui entrevistando, discutindo, fazendo esse apoio aos apoiadores. Em uma capital do Nordeste, eu comecei a fazer isso. Fiquei três dias lá trabalhando com os apoiadores. Quando você cria um espaço apropriado, as pessoas vão se expondo mais. Vários educadores físicos, fisioterapeutas, nutricionistas, estavam com medo de ficar ensinando o pulo do gato e perder cliente, perder legitimidade. Se todo mundo começa a entender de comida, o que a nutricionista vai fazer? Os enfermeiros, usuários, todos começam a entender sobre alimentação, risco alimentar, dieta, o que eu vou fazer, vou ficar inútil e eles vão me demitir. Aí o convencimento é o seguinte: nós vamos qualificar o seu papel, os casos graves de distúrbio alimentar, de nutrição, nós vamos lidar com o geral da comida, já que faz parte da vida humana, o usuário tem de saber, todo profissional da saúde tem de saber orientar. Agora, quando é que entra o nutricionista? Vamos fazer um pacto, que é assegurar o papel da profissão, disso preciso ser convencido e precisa ser feito. Mas há esse receio de ultrapassar o campo. De qualquer forma, o apoiador matricial tende a ser mais livre. Agora é um tipo de prática que a maioria das profissões não forma. A gente fez um levantamento, uma orientanda minha. Tirando a Psicologia, os cursos de saúde não discutem grupo, nem estratégias pedagógicas, falam em promoção à saúde, vocês tem de montar grupo, estratégias pedagógicas, construtivismo, aconselhamento, grupalidade, conflito. Isso não entra para Medicina, para Enfermagem, para Fisioterapia, nada. Aí se joga o apoio matricial para lidar com equipe, entrar na casa dos outros, lidar com paciente 
dos outros. Eu, para marcar o apoiador matricial, é o seguinte: digo, lembre-se de que você está entrando na casa dos outros, e que a etiqueta para entrar na casa dos outros é bater na porta e perguntar se posso entrar. Se convidar para sentar, sente, se não convidar para sentar, você conversa em pé, no corredor. A casa é dos outros e tem uma etiqueta. Se o expulsarem, acabou, não tem dialógico, não tem espaço coletivo. Nós vamos chegar à casa dos outros, o coordenador do caso é o outro.

Esqueci-me de falar uma coisa: fizemos um site, que é www.gastaowagner. com.br, onde colocamos o livro sobre apoio matricial, com autorização da editora. Estamos montando o site e há bastante texto, inclusive referências de outros grupos que estão trabalhando democracia institucional, enfim, uma série de grupos de São Paulo e do Brasil afora.

Muito obrigado! 